to the rough surface. The roughening of the surface may also explain why a stronger solution of tannic acid produces agglutination of the cells. Judging by the electron micrographs it appears that the protein covers the cell wall in shapeless masses, which produce the mottled appearance.

I wish to express my gratitude to Mr. D. Dresser, Department of Zoology, University of Edinburgh, for preparing the red blood cells, and also to the Melville Trust for Cancer Research who equipped the electron microscope laboratory in which the experiments were earried out.

Department of Zoology,

K. Deutsch

University of Edinburgh. May 4.

1 Boyden, S. V., J. Exp. Med., 93, 107 (1951).

a Ingraham, J. S., Proc. Soc. Exp. Biol. Med., 99., 452 (1958).

\section{Effect of Adrenalectomy on the Hormone Content of the Thymus in the Rat}

A LARGE number of publications have dealt with the influence of the adrenal cortex on the morphology of the thymus. Adrenalectomy has been found to result in an enlargement of the thymus ${ }^{1,2}$. The administration of various preparations of adrenal cortex (in large amounts) resulted in atrophy of the thymus. This was confirmed with purified cortico-adrenal extract ${ }^{3}$, cortisone $^{3}$, dehydrocorticosterone ${ }^{4}$ and deoxycorticosterone $e^{4}$. The same effect could be obtained with adrenocorticotrophic hormone ${ }^{5}$. Since the active fraction of the thymus can be obtained in a purified form ${ }^{6}$ and since a minute quantity of this fraction can be bioassayed?, we thought it of interest to investigate the effects of adrenalectomy on the thymus by these techniques.

50 male rats of $120-150 \mathrm{gm}$. were used. They were divided in groups of 5 animals and operated as follows:

(1) Bilateral adrenalectomy, three groups:

(a) Control,

(b) $200 \mu \mathrm{gm}$. of desoxycorticosterone acetate subcutaneously daily,

(c) $200 \mu \mathrm{gm}$. of cortisone acetate daily.

(2) Thymectomy, one group.

(3) Thymectomy, following 5 days later by adrenalectomy. The animals were autopsied 6 days after the adrenalectomy, that is 11 days after the thymectomy.

(4) Sham thymectomy and adrenalectomy. The thymus and the adrenals were removed and replaced

table 1. Hormonal Activity of Thymos, LympH Nodes and Splekn IN 'THE RAT.

\begin{tabular}{|c|c|c|c|}
\hline \multirow{2}{*}{ Group } & \multicolumn{3}{|c|}{ Activity (units per gm. of fresh organ) } \\
\hline & Thymus & Lymph node & Splcen \\
\hline Normal maies ... & $62 \cdot 5 \pm 5 \cdot 6$ & $20 \cdot 0 \pm 4 \cdot 0$ & $17 \cdot 0 \pm 4 \cdot 0$ \\
\hline Thymectomized .. & $一$ & $<6$ & $<4$ \\
\hline Adrenalectomized & $83 \cdot 0$ & $<10$ & $<B$ \\
\hline $\begin{array}{l}\text { Adrenalectomized } \\
\text { and thymecto- } \\
\text { mized .. }\end{array}$ & - & $<4$ & $<4$ \\
\hline $\begin{array}{l}\text { Adrenalec tomized } \\
+ \text { DOC }\end{array}$ & $79 \cdot 0$ & $1.4 \cdot 0$ & $10 \cdot 8$ \\
\hline $\begin{array}{l}\text { Adrenalectomized } \\
+ \text { cortisone }\end{array}$ & $39 \cdot 4$ & $<4$ & $<3$ \\
\hline Sham operated .. & $57 \cdot 4$ & $22 \cdot 0$ & $15 \cdot 8$ \\
\hline
\end{tabular}

without interruption of their vascular connections.

(5) The remaining 20 animals were autopsied as controls.

In every group, at autopsy, the thymus (except, of course, groups 2 and 3 ), the spleen and the lymph nodes (jugular and mesenteric) were pooled and extracted by the method of Bezssonoff and Comsa ${ }^{6}$. These extracts were bioassayed by the method of Comsa?. 'The activity found was expressed in guinea pig units per gram of fresh organ weight.

The 20 normal animals were divided in 4 groups of 5 animals each. Thus we obtained 4 normal extracts for control.

As can be seen from Table 1 , an active extract could be obtained from the normal thymus and a lessactive one from lymph nodes and spleen. Yet thymectomy resulted in an important decrease in the activity of lymph nodes and spleen. Thus it can be asserted that the hormone found in those organs came from the thymus. This could also be concluded from previous experiments on guinea pigs ${ }^{3}$.

Adrenalectomy resulted in a decrease of the activity of the thymus to less than half the normal level. In both lymph nodes and spleen, the activity decreased too; yet it cannot be said whether this decrease was parallel, since the activity fell below measurable limits.

These effects of adrenalectomy could be prevented almost completely by repeated injections of deoxy. corticosterone in normal amounts. Cortisone has no comparable influence.

The difference between the influence of deoxycorticosterone and cortisone is still more obvious if results are recalculated with a weight correction. Indeed, the relative weight of the thymus in our animals was (parts per thousand):

$2 \cdot 5 \pm 0 \cdot 3$ in normal rats,

$3 \cdot 3 \pm 0.5$ in adrenalectomized rats,

$5.4 \pm 0.6$ in adrenalectomized rats treated with deoxycorticosterone,

$3.2+0.4$ in adrenalectomized rats treated with cortisone.

Thus, for the total activity of the thymus in every group, we have:

In normals 23 units per $100 \mathrm{gm}$. living weight

In adrenalectomized

15 units per $100 \mathrm{gm}$. living weight

In adrenalectomized deoxycorticosterone treated

35 units per $100 \mathrm{gm}$. living weight

In adrenalectomized cortisone treated

14 units per $100 \mathrm{gm}$. living weight

It can be concluded that the hormonal activity of the thymus is conditioned by the adrenal cortex to a large extent. This influence of the adrenal cortex upon the thymus is supported by the deoxycorticosterone fraction. In other words, it seems to be connected with the mineralocorticoid and prophlogistic effects of the adrenal cortex.

I am grateful for the technical assistance of $\mathrm{A}$. Meiser.

Medical School, Homburg,

J. Comsa

Saar, Germany. May 29.

1 Jaffe, H., J.exp. med., 40, 618 (1924).

2 Marine, D., Manley, O. T., and Baumann, E. J., J.exp. mel. 40, 429

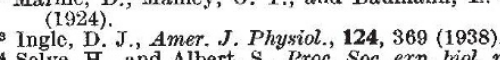

Selye, H., and Albert, S., Proc. Soc. exp. biol. med., 50, 159 (1942).

Crede, C. H., and Moon, W., Proc. Soc. exp. biol. med., 43, 44 (1940).

Bezssonoff, N. A., and Corna, J Ann. d'endocr.

Comsa, J., J. de physial. (Paris) 